\title{
Retention of Email Records in New Zealand Tertiary Institutions
}

by

\section{Morgan Gradwell}

Submitted to the School of Information Management,

Victoria University of Wellington

in partial fulfilment of the requirements for the degree of

Master of Information Studies 


\begin{abstract}
Research problem: Despite its ubiquitous usage, there has been a lack of research into the New Zealand public sector's use of Information Communication Technologies (ICT). Email records pose a particular problem, especially when their management is left in the hands of the end user. This poses a risk where the Public Records Act 2005 (PRA) is concerned. The research within this paper explores the retention and disposal of email records within New Zealand tertiary institutions so that the attitudes of information professionals responsible for the retention of email records are captured, as are the perceived risks of managing such records.
\end{abstract}

Methodology: For the purpose of this study quantitative data was collected to determine the understandings, attitudes, and concerns of information professionals. The unit of analysis was drawn from a population consisting of information professionals within New Zealand tertiary institutions. For the purpose of this research, tertiary institutions that operate as publically funded crown entities were identified. The research was undertaken with a Continuum perspective.

Results: Within tertiary institutions, the issues of email management do not appear to lie with the appraisal policies or retention and disposal schedules. Instead the main risks associated with email records stem from the original creator, or end user, being responsible for identifying what emails are records and managing them appropriately. The implementation of electronic document and records management systems (EDRMS) varied between institutions, but majority of the research participants identified them as being of importance to the capture and management of email records.

Implications: The findings show that there is a lack of empirical evidence into how the end users within tertiary institutions are treating email records. Further study is needed within tertiary institutions as well as the wider public sector regarding the risks posed by the mismanagement of email records. There is also the need for further research into the implementation of EDRMS, and how EDRMS vendors in New Zealand are meeting legislative requirements.

Keywords: Email - Retention - Risk - EDRMS - Tertiary Institutions - Public Records Act 2005 


\section{Acknowledgements}

A very special thank you goes to my supervisor Gillian Oliver for her guidance and encouragement throughout this project. Her support has kept me on track and helped to make this whole thing achievable.

I would also like to thank my dear friends here in Wellington who have kept me sane throughout this process. Whether it was bouncing ideas off one another or going out for a coffee, simply knowing that you were there has been invaluable to me.

Thank you to the information professionals who have contributed their time and thoughts to this research. 


\section{Contents}

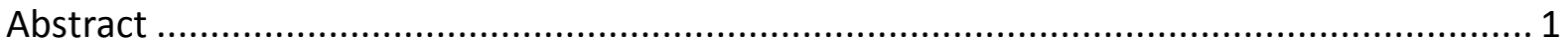

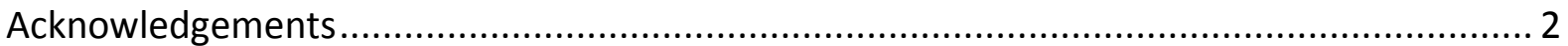

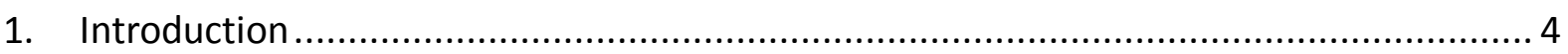

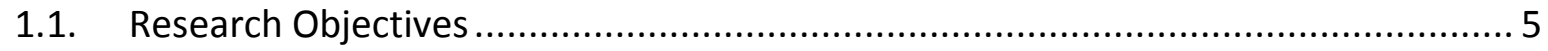

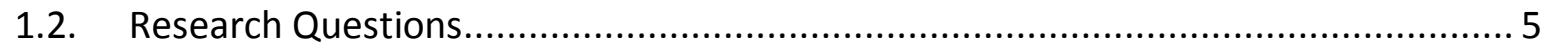

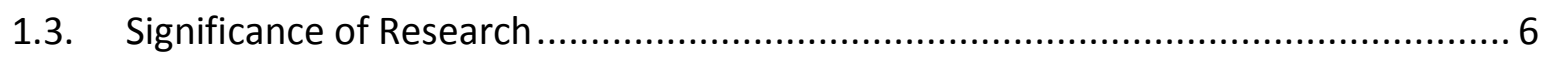

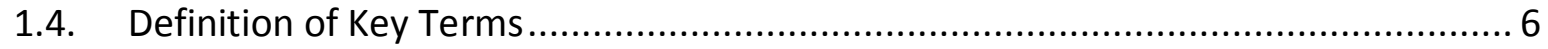

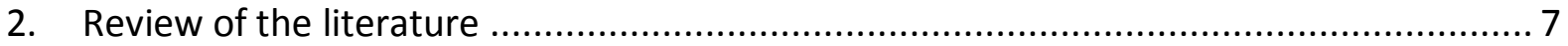

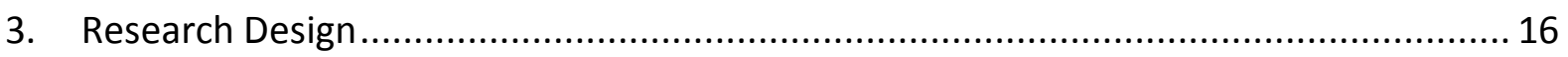

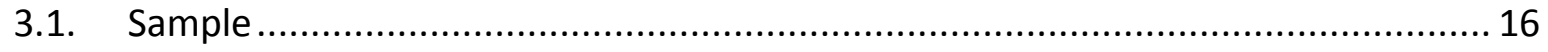

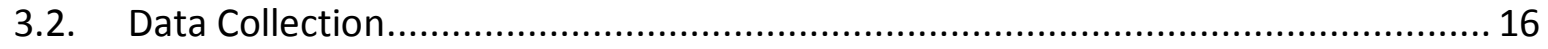

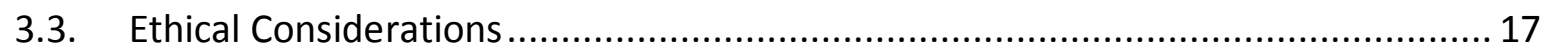

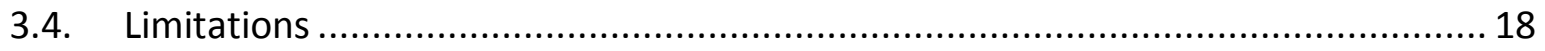

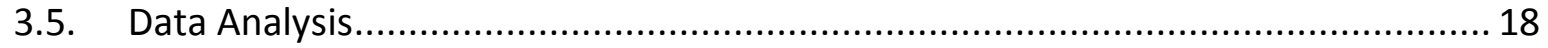

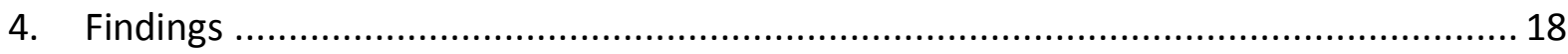

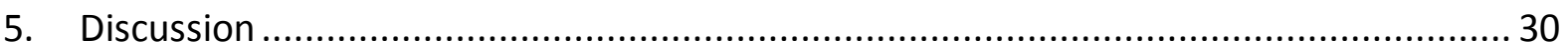

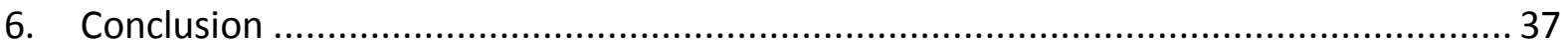

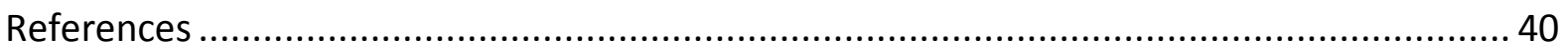

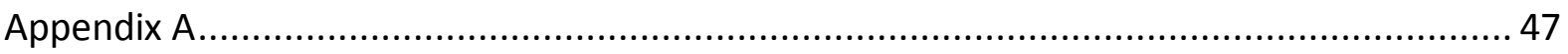

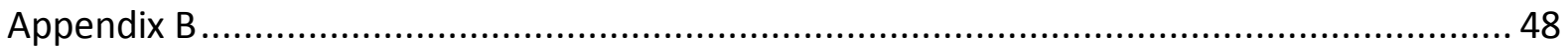

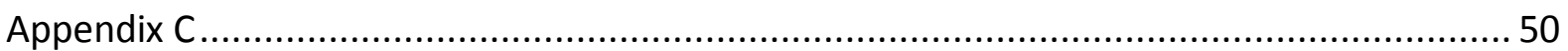




\section{Introduction}

Email as a form of communication has become a ubiquitous feature of life in New Zealand since its inception in the 1990s. The coming of email created a communications channel to challenge that provided by the postal system affecting business operations in both the public and private sectors. One of the main changes being that official correspondence is no longer confined to the office space. With more than half of all New Zealanders owning smartphones, electronic records such as emails can be created and accessed from almost anywhere in the country and internationally (Institute of Culture, Discourse \& Communication, AUT University, 2013; Statistics New Zealand, 2013). There is currently a lack of insight into the New Zealand public sector's use of information communication technologies (ICTs), particularly how email is used within organisations and how it is being governed. A one-off survey was conducted in 2006, exploring the government's use of ICTs (Statistics New Zealand, 2006). At the time, email attachments made up 61 per-cent of file sharing within organisations (2006). Given the growth of technology since, it is difficult to say if this number has grown seeing as there are now many different platforms for file sharing now. Whether the methods for recording these interactions have improved since is another matter.

The current knowledge gaps and growth rate of the use of email as a form of communication and file sharing show that further investigation into the use of email within public sector organisations is needed. Effective management of emails is essential for institutions to meet various legislative and accountability requirements, administrative needs and to protect their rights and reputation (Ismail \& Jamaludin, 2009). However, emails are often viewed as ad hoc forms of communication due to their transient nature and the text taking on elements of written and spoken conversation (Baron, 2000). This means that they do not naturally align with traditional recordkeeping methods (Ismail \& Jamaludin, 2009; Statistics New Zealand, 2006). Their importance as records within the public sector is inescapable as they are evidential in nature. The Public Records Act 2005 (PRA) defines records as, "information, whether in its original form or otherwise, including (without limitation) a document, a signature, a seal, text, images, sound, speech, or data compiled, recorded, or stored, as the case may be... by means of any recording device or process, computer, or other electronic device or process (Department of Internal Affairs, 2005)." For 
this reason the attitudes of information professionals towards the associated risks of mismanagement was also worthy of investigation.

\subsection{Research Objectives}

The objective of this study was to gain an understanding of the current appraisal measures being used within New Zealand public sector institutions specifically with regards to emails that are subject to the PRA. Current practices and attitudes of information professionals has been analysed and examined according to the risks associated with the retention and disposal of email records.

The scope of the research has been restricted to New Zealand tertiary institutions that are Crown Entities, and therefore subject to the PRA. The reason behind this decision is that the population size was appropriate for the research being undertaken. By focussing on tertiary institutions the research will provide new insight to the particular sector, as well as providing a foundation for wider research in the public sector.

The research was undertaken to identify any current gaps in practice with regards to the management of email records. It also sought to gain insight into records managers' attitudes towards the risks of mismanagement, and the at times tenuous relationship between information professionals and information technology (IT) staff in tertiary institutions. The research did not aim to produce a governance or best-practice framework itself, but rather identified the needs within tertiary institutions to provide a foundation for further research within the wider public sector.

\subsection{Research Questions}

The research questions allowed for a variety of themes to be explored in this research:

- Within New Zealand tertiary institutions that are subject to the PRA, what appraisal measures are currently in place for digital records, specifically emails?

- What are the main risks involved with the retention of email records as perceived by recordkeeping professionals within the tertiary sector?

- What are the current gaps between governance frameworks and actual practice as perceived by information professionals in the tertiary sector? 
- What is the current attitude of information professionals within the tertiary sector towards IT staff and higher level decision making?

- In determining email retention, what are the collaborative efforts with the IT department of tertiary institutions, if any?

\subsection{Significance of Research}

This research was undertaken within tertiary institutions to develop existing knowledge on the risks associated with the mismanagement of email records, and investigate the actions and attitudes of public sector information professionals towards these risks. There needs to be an understanding of email records as being containers of evidential value in accordance with legislation. As Archives New Zealand (2014) states, it is not practical nor necessary to keep every individual record. However, it is important to identify and preserve those records that:

- Document the rights and entitlements of New Zealand's citizens.

- Enable the efficient and accountable operation of the New Zealand government.

- Preserve information about New Zealand's national history for future generations.

The desired outcome of this research was not to provide prescriptive guidance, but it instead provides an overview of the current state on the management of email records in tertiary institutions. The research is relevant to both the management of email records within the wider New Zealand public sector, and to the management of other forms of digital records.

\subsection{Definition of Key Terms}

An email (electronic message) is a message sent (a) using a telecommunications service; and (b) to an electronic address (Archives New Zealand - Te Rua Mahara o te Kāwanatanga, 2014b).

In New Zealand, a public record is a record or a class of records created or received by a public office in the conduct of its affairs (Department of Internal Affairs, 2005). 
Appraisal is the process of identifying the records that should be retained permanently as public archives and those records that should be destroyed once an organisation's business and accountability requirements have been met (Archives New Zealand - Te Rua Mahara o te Kāwanatanga, 2014a).

Disposal is the range of processes associated with implementing records retention, destruction or transfer decisions which are documented in a disposal authority (Archives New Zealand, 2014a). Section 4 of the PRA outlines the possible types of disposal as: the transfer of control of a record; or the sale, alteration, destruction, or discharge of a record (Department of Internal Affairs, 2005).

An information professional is someone who collect, records, organises, stores, preserves, retrieves, and disseminates printed or digital information (Greer, Grover, \& Fowler, 2007).

An electronic document and records management system (EDRMS) is a software application that manages a range of digital information, including word-processed documents, spreadsheets, emails, images and scanned documents. An EDRMS can combine both document management and records management functionality (National Archives of Australia, 2011).

\section{Review of the literature}

The transition to digital has created both opportunities and cause for concern within the New Zealand public sector. By 2017 the New Zealand government aims to have public services mostly in the digital realm with an associated Digital Continuity Action Plan (Department of Internal Affairs, 2014). This is not only to increase the efficiency within the public sector, but it is also to benefit the public through increased services, accountability and transparency. It is claimed to be "a world first initiative to prevent important public records being lost and ensuring that today's information is available tomorrow (Archives New Zealand, 2011)."

Currently New Zealand local authorities and public offices can refer to the Records Management Standard for the New Zealand Public Sector and General Disposal Authorities 6 
and 7 for basic appraisal and disposal guidelines (Archives New Zealand, 2014b, n.d.-a) . There are also considerations to be made in the digital environment with the complimentary Digital Recordkeeping Standard S5 that should be consulted to review the functionality of existing electronic systems (Archives New Zealand, 2010). While digital records are seemingly being captured with some regularity now, there is no guarantee that they will retain the vital characteristics of records in the long term: authenticity, reliability, integrity and usability (Archives New Zealand, 2014b).

It has been recognised that tertiary institutions have different requirements to the rest of the New Zealand public sector with specific appraisal, retention and disposal guidance being provided for universities, polytechnics and institutes of technology (Archives New Zealand, n.d.-b, n.d.-c). Tertiary institutions are still subject to the PRA and under the legislation tertiary institutions must:

- Create and maintain full and accurate records which must be accessible over time.

- Obtain the authority of the Chief Archivist in order to dispose of public records. Disposal is the archival term for the ultimate fate of records, and usually means their destruction or transfer to Archives New Zealand (Archives New Zealand, n.d.-b, n.d.-c).

The available retention and disposal guidance for tertiary institutions provide beneficial examples of records and their retention periods, making note of email records where necessary (Archives New Zealand, 2009c, 2014c). This allows for general staff or those responsible for the management of email records to delete personal or ephemeral emails when they are no longer administratively required.

Information professionals responsible for recordkeeping within tertiary institutions have their own unique set of needs and obligations. In 2009 a General Disposal Authority for Universities was developed, as it was the first time New Zealand universities have been included in public recordkeeping legislation (Archives New Zealand, 2009b). In their research and consultation it was found that while the functions and activities are relatively consistent across all universities, the recordkeeping systems vary (Archives New Zealand, 2009b). It was also found that the roles and responsibilities regarding recordkeeping were starting to 
be addressed by universities and there were well established roles for archivists in a number of institutions (Archives New Zealand, 2009b).

The changing nature of records and frequent alerts to breaches and misuse has meant that records management has gradually moved from a position on the very periphery of organisational attention, towards a far more central role as organisations aim to meet their legal obligations (Nguyen, Swatman, \& Fraunholz, 2007). Recent examples include Hillary Clinton's use of an unsecured personal email account for her four years serving as Secretary of State (Evans, 2015). Until January 2015 Clinton also failed to preserve her correspondence on the State Department's servers which is required of officials under the US Federal Records Act (Evans, 2015). Closer to home is the ongoing investigation into New Zealand Prime Minister John Key's deletion of text messages from his ministerial phone (Vance, 2014, 2015). The demand for greater accountability to citizens has led to increased transparency, more open government, and citizen rights to information (Shroff, 2005). This is reflected in four interrelated pieces of legislation:

- The Official Information Act, 1982

- $\quad$ The Privacy Act, 1993

- The Electronic Transactions Act, 2002

- $\quad$ The Public Records Act, 2005

Despite the available information, a 2008 survey into the New Zealand public sector found that there is a substantial knowledge gap among the respondents regarding how to identify emails for retention and how to retain and appropriately manage those of significant value (Lips, Rapson, \& Hooper, 2008, p. 50).

There are many risks to the evidential requirements of digital records that are created within the public sector. Many of the concepts are not new, but records managers need to be aware of these risks and their potential outcomes. They include:

- Exponential data growth has led to the build-up of large volumes of information in the form of email accounts on servers and in email archives (Lappin, 2014). One resolution to this problem is 'big bucketing' or the 'big bucket' effect (Findlay, 2014; Lappin, 2014). This method of appraisal is often conducted at a macro level in which 
everything is considered to be a record. This creates volumes of unappraised digital records, or as the management of them is left to third-party agencies there is lack of control around records meaning that their role as evidential documents is compromised (Findlay, 2014).

- Records management has now reached the "tipping point" with regards to the records themselves and the technology used (Cumming \& Findlay, 2010). Technological obsolescence puts public sector digital information at risk. For example in Archives New Zealand's Digital Continuity Plan, it was reported that 67 per cent of New Zealand public sector agencies hold information that they can no longer access (Archives New Zealand, 2009a).

- Who is to take ownership, or responsibility of electronic records (Archives New Zealand, 2006b; Bearman, 2006)? This differs greatly between countries and organisations, with some researchers such as the Pittsburgh Project Model believing that that electronic records must be kept under the control of trusted recordkeeping authorities and systems at all times (Bearman, 2006). Other jurisdictions such as Canadian Government Agencies see ownership as lying with the original creator (Zwarich \& Park, 2013). This can lead to the reliability of records being compromised as there is always going to be a level of human error (Feary, 2013).

- The at times tenuous relationship between information professionals and IT professionals. In many organisations that are under pressure archivists struggle to "get a seat at the grown ups' table" to advocate for improved governance and accountability in business projects or IT systems (Cumming \& Picot, 2014). This means that key business decisions can be made with no reference to legislation or carefully developed disposal authorities (Findlay, 2014). Records and their metadata, can be left behind and lost, or unnecessarily carried forward.

Exponential data growth was the first risk to be mentioned with regard to digital records. In the digital environment, not all documents that are created are appropriate to be filed as records; some are purely ephemeral or personal, some merely contain a re-iteration of information held elsewhere (Bearman, 2006). Like New Zealand, the UK Public Record Office has included digital records in their recordkeeping legislation, taking the functions of the records into account. Their guidelines state that: 
Corporate guidance should aim to ensure that electronic records which possess the same functional and documentation characteristics across the organization are retained for the same length of time, and are disposed of in the same way. Care should be taken to ensure that all copies of an electronic record are brought within this framework, including duplicate copies stored in different locations, and electronic records from which a paper filing copy has been taken (emphasis added) (Public Record Office, 1999).

Organisational policies or guidance are an important factor when it comes to managing electronic records as they lay the foundation for good practice. This is because they guide both the creators of the records, and the information professionals who are responsible for their ongoing management and preservation. The responsibility of records management can differ greatly between countries and institutions. Records retention is particularly problematic in an email system where individual users, instead of information professionals, manage the documents in the institution (Zwarich \& Park, 2013).

Ismail and Jamaludin $(2009$, p. 137) believe that policy is required for three main purposes:

- Ensuring that the organisation has the necessary information to form or reconstruct activities and transactions that have taken place.

- To ensure the location and access to information.

- To establish the context of records. For example, who created them, during which business process, and how records are related to other records.

To address the issues associated with digital records, this research was undertaken with the Records Continuum principles in mind. A Continuum perspective provided a solid theoretical framework and aligned the research with current New Zealand recordkeeping practice (Archives New Zealand, 2012; Upward, 2005). According to these principles, email records that are subject to the PRA (Department of Internal Affairs, 2005) should be captured and appraised at the time of their creation, and organised appropriately for retrieval (Archives New Zealand, 2014b). Operating within the New Zealand public sector, the Records Continuum model is of great importance when considering the use of email within tertiary institutions. The Continuum model was developed in the 1990s by scholars at Monash University who were finding the traditional Lifecycle model inadequate for managing the growing volume and complexity of electronic records (Upward, 1996). 
The Continuum model allows for a record to exist and be interpreted in many dimensions across time. For example, they can be created (as a record) and created again (either in new contextual groupings or in reinterpretation) without the need for a linear approach to time (Lewellen, 2015). Lappin $(2014$, p. 1) provided a good business-based analogy for the Continuum when he wrote:

We may think of a records continuum spreading out in each direction from the person(s) carrying out a piece of work, to their immediate colleagues and line management chain, and then, embracing people further removed in time and or/space - the successor(s) to the person(s) carrying out the work; auditors; legal and compliance colleagues.

This way of thinking about records moves away from the Lifecycle model that involves sequential control of records from their creation to their inception by the archives. For the majority of the twentieth century this model worked well for physical records, but the continuity and life span of electronic materials required a different model. Working out in concentric circles, the axes of the Continuum model represent the people, purposes, processes and systems that create, shape and manage information (appendix A). The dimensions comprise the spectrum from private to public in which information resides and the records cycle of: creation, capture, organisation, and pluralisation.

The objectives of the existing research demonstrate a development within the Continuum model as the focus shifts from the creation of digital records, to the capture of them. The context of individual institutions is of value, but it is the appraisal processes and capture systems that are most important within the public sector due to the evidential value of the records. Previous research has focussed on the public sector's creation and use of digital records more so than the capture and organisation of them as records. Johnston (2012) provides such an example with her research into the attitudes of reference archivists at Archives New Zealand towards the use of social media. A thematic analysis was used to identify themes and while there was optimism with regards to the new technologies, there were also concerns about the lack of policies and plans in place for digital records of this kind (Johnston, 2012).

Research undertaken by Stoks (2012) was based around the capture of social media records by Australian government departments. Stok's research followed on from a 2012 study 
which was undertaken by the State Records Authority of New South Wales (SRNSW) which showed that there was still a lack of awareness in government (even among information professionals) that some digital content can be treated as records (Cumming, 2012; Stoks, 2012 , p. 17). In order to present the information in a readable way, the Continuum model was used (Stoks, 2012, p. 9). With regards to email management, Lips, Rapson and Hooper (2008) investigated the behaviours and practices of individual public sector employees. The basis for their research being that until that point, there was no empirical evidence of how individual employees in government agencies identified and managed email messages. (Lips et al., 2008). In the second phase of their research, Lips and Rapson (2009) undertook research on the capture of electronic records by New Zealand public servants, investigating how they identified and managed electronic records created through the use of Information and Communication Technologies (ICTs), also referred to as 'Web 2.0' technologies in the paper (p. 5). Their research was undertaken with personal, anticipated information need theory, and interventionist and event-oriented frameworks, but for the purpose of this research it can also be viewed from the 'capture' axis of the Continuum model.

A trusted environment is essential to ensuring an organisation's accountability in their activities, as public acceptance depends largely on trust and confidence (Ismail \& Jamaludin, 2009). Further demonstrating the shift to the 'capture' of digital records, Dorner (2009) sought to identify why there was a low awareness and activity of digital preservation in the New Zealand public sector. His research also looked into the organisation practices regarding the creation of digital material, short-term storage practices, and long-term depository arrangements (Dorner, 2009, p. 342). Of the risks that were identified, the roles of key players within the New Zealand public sector was identified as being of great importance for the advocacy and adoption of digital preservation (Dorner, 2009). In her research, Stoks found the same issues as Dorner had several years prior (Stoks, 2012). Of those that were interviewed for her research, most of those capturing records were not very confident that they were meeting their legal obligations, and that they were still struggling to raise awareness among their colleagues of their obligations (Stoks, 2012).

Existing research demonstrates that enforcing appraisal policies and implementing electronic systems that store digital records (such as email) is a challenge for information professionals. Whittaker, Bellotti, \& Gwizdka (2006) wrote that it is possible that the 
informal nature of email contributes to the use of the tool as a personal information management system involving: task management, personal archiving, and contact management. This indicates that records may not be handled appropriately if the materials are not recognised as records in the first instance. In attempts to assist with the management of electronic records, government departments and institutions have been implementing EDRMS (Duranti, 2010). EDRMS are also implemented in response to legislative imperatives such as the PRA as they assist with the capture of records and their evidential value. (Lewellen, 2015). In the New Zealand public sector with the Digital Continuity Action Plan, electronic records are required to use compliant metadata in order to maintain the context of the records for the planned transition from their respective organisation's EDRMS to the national repository when they are disposed of (Lewellen, 2015). An important implication is that these systems transfer the responsibility of recordkeeping from the information professionals to the end users (Joseph, Debowski, \& Goldschmidt, 2012). Consequently, end users now have responsibility for both identifying documents worthy of retention and applying descriptive metadata to those records (Lewellen, 2015).

Even when recordkeeping systems are brought into institutions there is the risk that they are not going to be taken up by those working within those institutions. Part of this is because email communication often takes on a conversational and personal tone (Baron, 2000). This requires the users, or staff within the public sector organisations, to take the responsibility to differentiate between what needs to be kept as a documentary record, and what can be destroyed as more trivial work-related material or personal correspondence (Archives New Zealand, 2006a). It has been found that relying on staff to categorise every email properly at creation or receipt will likely result in user frustration or improper categorisation, especially when the volume of email is considered (Ward, 2006). What is of concern is that Lips, Rapson and Hooper (2008) found that a substantial number of public sector employees had not received information explaining how to keep emails of significant value, while thirty-two percent of respondents indicated that they had not received any information at all on how to identify emails for retention (p. 50).

When a government employee does identify an email for retention, they take on the responsibility to maintain the evidential aspects of the record (Lips et al., 2008). The first 
"moment of risk" in the life of an electronic record is at the moment of capture and this determines whether it is saved in the user's systems at all, or if it retains information of value (Bearman, 2006). It has become widely accepted that electronic records are at greatest risk of losing their 'record-ness' at moments when they are transitioning between states. A simple example of this is when control is being transferred between different systems (Bearman, 2006). Loss of metadata is a key concern when it comes to the preservation of a record's authenticity and its disposal. There has been a growing discussion within the recordkeeping community that the original bit-stream should be captured along with migrated formats as a kind of double insurance (Bearman, 2006). In order to save a record, the captured document needs to be accompanied by adequate metadata relating to content, structure, and context to establish its value as evidence (Bearman, 2006). Yet it is the act of manually lodging the electronic file into an EDRMS that provides it with its legitimacy (Joseph et al., 2012; Lewellen, 2015). Both content and metadata need to remain together, unaltered, and usable over time.

This has prompted many professionals and researchers to look towards the automation of capturing records. As digital records are being appraised on a more regular basis there is more room for developments and innovation. Whereas previously there was research into why there was a lack of integrated technology in institutions (Johnston, 2012), more recent studies such as those undertaken by Lappin $(2014,2015)$ have provided some insight to the potential automation of appraisal and the classification of records. In his research Lappin investigated the idea of automation or auto-classification of digital records - particularly email. Behind this research was the National Archives \& Records Administration (NARA) developing its Capstone programme (National Archives \& Records Administration, 2013). This programme offered government agencies the option of using a more simplified and automated approach to managing email (National Archives \& Records Administration, 2013). Investigating the risks of the 'tipping point' of digital records, Cumming and Findlay (2010) analysed a series a of case studies from a specific Australian state's public sector. One of their case studies focussed on the University of Sydney which has automated its records management processes such as disposal and access classification (Cumming \& Findlay, 2010). As a consequence the student management function now has greater integrity and accountability. 
While studies such as Stoks' (2012) has provided insight into the methods agencies are using to capture digital records, as well as the case studies by Cumming and Findlay (2010) and Lips, Rapson and Hooper (2008), there was certainly scope for the research that was undertaken here in New Zealand based on the Continuum model. Appraisal decisions need to come not at the end of the record's use as prescribed in the traditional Lifecycle model but at their inception if the management of email is considered from a Continuum perspective. Some of the studies referenced here are several years old now, but the risks associated with the management of email records need to be considered on an ongoing basis. This requires information professionals to be actively involved in sector developments and informed in current best practice so that they are in the position to impart their knowledge on staff.

\section{Research Design}

Data for this research has been collected as a quantitative study to gain insight on the appraisal of email records within the tertiary sector. As the attitudes and opinions of the information professionals were also sought, the research was undertaken with interpretivist paradigms in mind.

\subsection{Sample}

The unit of analysis was drawn from information professionals working within New Zealand tertiary institutions, consisting of 29 institutions altogether. For this research, tertiary institutions that operate as publically funded crown entities were identified through the Ministry of Education website (Ministry of Education, 2015). The contact details of information professionals working within these institutions were acquired online via each institution's website. For smaller populations (that equal 100 or fewer), there is little point in sampling rather than surveying the entire population (Gay, Mills, \& Airasian, 2009).

\subsection{Data Collection}

The data for this research was collected in one phase. A mixed-methodology inquiry would have been preferred as they allow the research to generate deeper and broader insights into the research subject (Greene \& Caracelli, 1997). However the research was conducted within a restricted time-frame, and that this is a preliminary study, there was not the opportunity for a mixed-methodology to capture both qualitative and quantitative data. 
For the purpose of this study, quantitative data was collected to determine the understandings, attitudes, and concerns of information professionals. To best serve the purpose of this research an online questionnaire was developed. The questionnaire was not based on any previous surveys, but a pilot test was undertaken by several information professionals which assisted with the simplification and direction of the questions. An email containing participant information and a link to the questionnaire were sent to the identified information professionals during April of 2015, with the first email sent Monday 20 , and then subsequent reminders were sent the following 2 weeks (appendix B).

To benefit from the experiences of information professionals, rating scales and close-ended questions were complimented by open-ended questions in the online questionnaire (appendix C). Leedy \& Ormrod (2013) wrote that when rating scales are used it is easier to quantify people's behaviours or attitudes, however it is possible that valuable information that qualifies people's responses may be lost. By including discussion boxes and three openended text questions, insight into respondents' answers and the possibility of yielding information for further study was sought.

\subsection{Ethical Considerations}

Approval for this survey was obtained from the School of Information Management's Human Ethics Committee (HEC) in March of 2015.

Respondents completing the online questionnaire remained anonymous, with the condition that the findings from the research were sent out to all initial points of contact. Due to the small sample size, special precautions were taken to maintain total anonymity. Accordingly, demographics such as age, gender, institution of employment, and job title were not asked for. The only identifiable information requested was the size of the recordkeeping team. A benefit of seeking minimal demographic information from the research participants is that any attempt at social desirability bias (portraying their organisation in a better light), or attempts to please the questionnaire has been negated (Leedy and Ormrod, 2013).

Qualtrics software was used to develop, distribute, and manage the questionnaire and anonymity was further ensured by the software not identifying the ISP address of participants. The data is only accessible by the researcher and their supervisor, and all electronically stored information will be deleted after two years. 


\subsection{Limitations}

Time constraints have been mentioned, driving the need to restrain the data collection to one method (quantitative). A limitation of questionnaire-style surveys is that there is the risk of a low return rate, and results can be limited based on the survey questions (Leedy \& Ormrod, 2013). Along with the small unit of analysis, a concern was that the surveyed sample may not have adequately represented the population even after pilot testing the survey

Due to the anonymity of the survey it was not possible to ask follow-up questions or have any engagement with participants external to the questionnaire. Research findings are derived from the interpretations of a single researcher: through content analysis and thematic analysis. This means that the researcher's cultural bias may have affected results.

\subsection{Data Analysis}

The results of the survey questionnaire have been analysed as quantitative data. The survey software Qualtrics uses a range of variables to generate statistics, and data from Qualtrics was used to generate additional graphs using DataCracker.com.

Any additional information that fell outside of statistical data sets has been coded and developed into a thematic analysis. The open-ended text questions were analysed separately to support the data from the survey. The data were coded according to concepts and examined to see if there was any consistency in responses between different tertiary institutions.

\section{Findings}

Of the 29 institutions that received the survey invitation, 14 responded. With questionnairestyle surveys there is the risk of a low return rate, but a $50 \%$ response rate is enough to draw conclusions of the wider tertiary institution population (Leedy \& Ormrod, 2013).

The participants answered all multi-choice questions, with many expanding on each point in the discussion section although it was not compulsory to do so. The least commentary came from the discussion on the use of EDRMS with only six comments. Otherwise, all discussion sections received 10 or more written responses. 
Discounting responses that respondents took several days to complete, the mean time for survey completion was 12 minutes, 12 seconds which falls below the pilot survey estimated time of 20 minutes.

Question 1. How many full time equivalent staff members are employed to manage records at your tertiary institution?

This was one of the preliminary questions to determine the current circumstances in New Zealand tertiary institutions. The question was mandatory, and was the only demographic question included in the questionnaire to maintain anonymity. The majority of responses (42.9\%) indicated that there were $0-1$ full time equivalent staff. $35.7 \%$ indicated that there were 2-3 FTE information professionals, and $21.4 \%$ had 4+ FTE.

Questions 2 \& 3. Does the records management team look after administrative records?

\section{Does the records management team look after student records?}

One of the unique aspects of tertiary institutions is that there are different sets of records that need to be managed. There are staff and administrative records, as well as student records. The creation and use of these records can take place in a multitude of ways and simultaneously as the Continuum takes into account.

These questions were mandatory so there was a $100 \%$ response rate. There were no significant differences in responses between questions. For administrative records, $57 \%$ of the respondents manage them, while $43 \%$ do not. For student records, $43 \%$ of respondents managed them, while $57 \%$ did not. That is not to say that the results were neatly split into respondents who were responsible for one set of records or the other.

Figure 1 


\section{Administrative versus Student records}

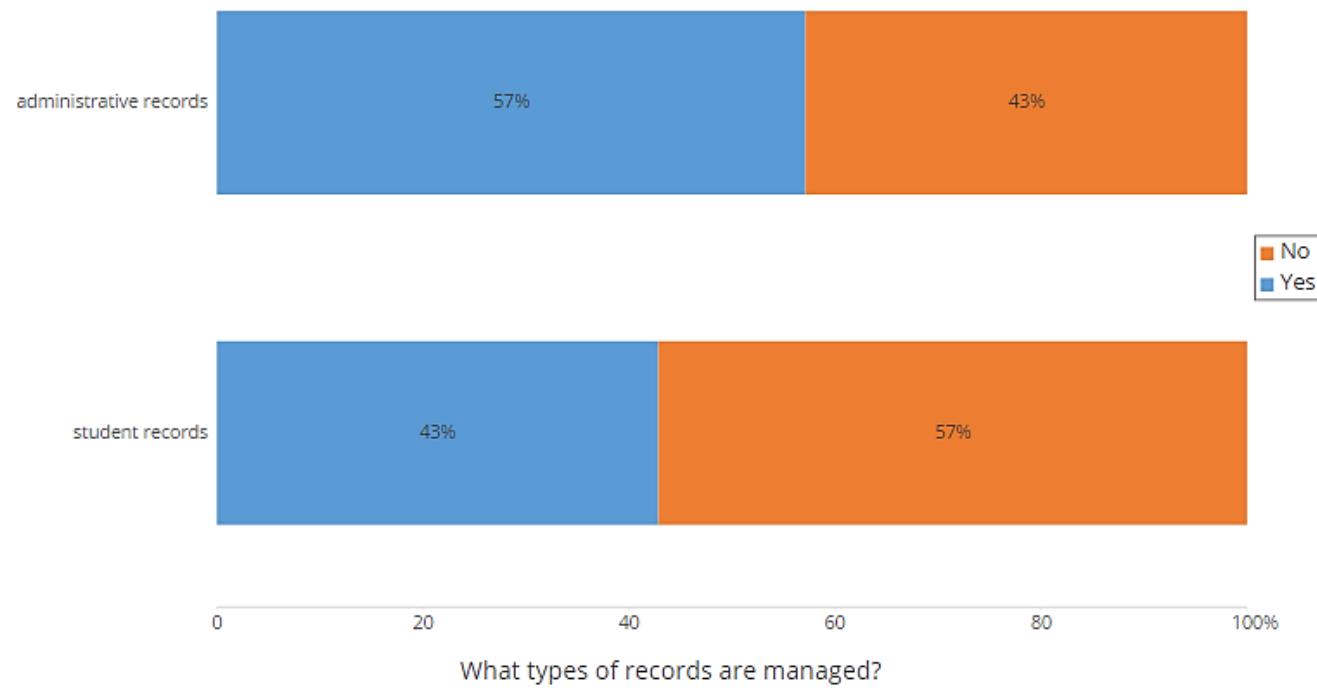

Question 4. Do you have a retention and disposal schedule?

This was the first in a series of questions to find out information about the existence and use of appraisal policies and retention schedules within tertiary institutions. Particular attention was paid to email records. Using Qualtrics's tools, there was skip logic in place so that if questionnaire participants had answered 'No', or 'Unsure' then they would have been redirected to Question 9 "Do you have an electronic system for the management of records (e.g. an EDRMS)?".

The unanimous response to this question was 'Yes' at $100 \%$.

Question 5. Are there procedures for the retention and disposal of email records in your policies?

This was the first of three questions to further investigate the consideration participants have made toward the retention and disposal of email records. Ten respondents answered 'Yes', while four answered 'No' to their institution's policies taking the retention and disposal of email records into consideration. Zero respondents responded as being 'Unsure' 
about their policies. Ten participants expanded on their responses in the accompanying comments section.

Several points of interest were brought up in the discussion section. Three respondents pointed out that email was not specifically separated as a format, and that distinctions were determined by content instead. For example, retention is based on the documents or correspondence within an email. The questionnaire respondents also addressed the issue of where the responsibility of records lies in New Zealand tertiary institutions. One wrote that email retention is, "Written in to policy and procedures, but whether staff comply is another matter and not monitored."

Going back to Questions 2 and 3, one of the respondent's commented that the phrase to "look after" student or administrative records is redundant in a tertiary environment as the information professionals provide guidance and advice, but do not have any direct control over the records themselves.

Question 6. Does the actual practice of managing email records reflect retention and disposal policy?

Following on from Question 5, this was the first of two scaled questions included in the questionnaire. Ranging from 1 to 5, 'Not very reflective' to 'Highly reflective', survey participants had to select how the actual practice of managing email records reflected their retention and disposal policies.

Of the results the mode was the minimum result, 'Not very reflective' with eight participants selecting this. The highest selected value on the rating scale was the middle value 3 , with the mean sitting at 1.64 . The skew is show below with the median sitting at 1. 
How does the actual practice of managing email records reflect retention and disposal policies?

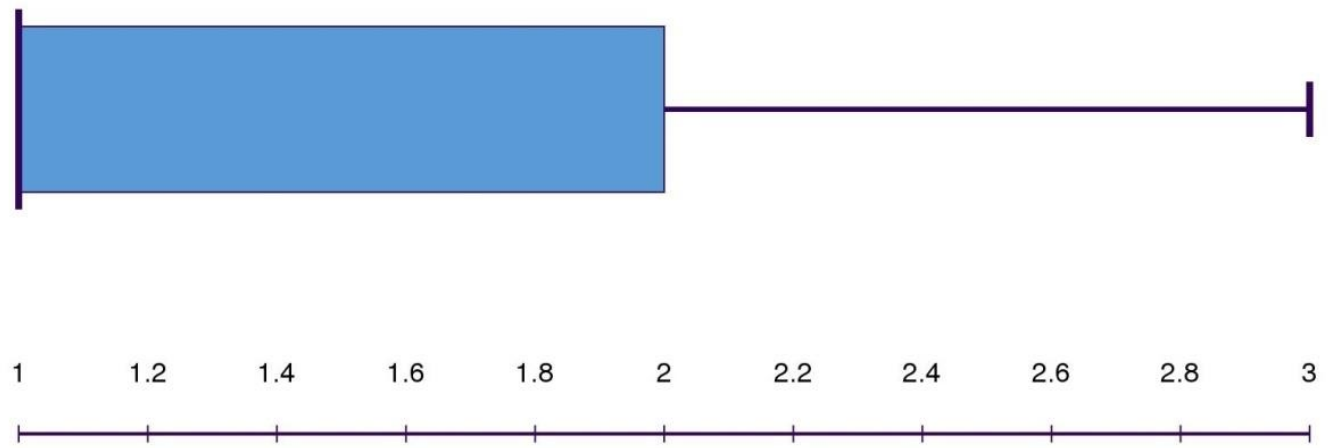

Eight questionnaire participants expanded on their responses in the discussion section. One of the respondents commented on having a "Quality Management" manual policy which applies to all staff and outlines their responsibilities. Another respondent mentioned that their institution has a specific "Records Management Policy" in place, which does not specify retention requirements, but rather it references back to more official documentation.

For a respondent whose institution had implemented SharePoint it seems that they had more control over emails than those without, as emails in their institution are assigned appraisal and sentencing metadata as soon as they are uploaded by the end user.

The lack of control over email management for participants without an EDRMS was brought up. One respondent wrote, "Email is stored on individual Outlook accounts. It is possible that some staff export email for storage in our share drives but I have no idea where they are stored or what format they are stored in. At present we are developing a records management system which will give us some measure of control over email that is exported and store on the share drives." Another wrote, " "The university does not have a dedicated EDRMS or equivalent, so lacks the technical infrastructure to properly support staff manage their email-as-records in contextualized repositories." 
Question 7. What are the gaps between your schedule and the management of email records?

The final of the three questions regarding the retention and disposal of email records, this was the first open-ended text question of three included in the questionnaire. Answers were not mandatory, but all 14 participants responded. Two respondents did not understand the nature of the question, but the other 12 responses covered issues around staff and recordkeeping systems. From the open text discussion section of both this question and Question 6, the perceived gaps in the management of email records are caused by two main issues: the systems in place, and the lack of accountability by the staff within the tertiary institutions.

Regarding systems that are in place one respondent wrote that, "The gap is technology and process driven, inasmuch as there is no central service into which email can be transferred/sentenced." The constraints around not adopting an EDRMS were mentioned by another respondent who wrote, "University culture, general resistance to change and a lack of funding."

Even with an EDRMS in place there are still perceived gaps with one respondent stating that, "We do not have an easy way of transferring emails to our EDRMS... Staff manage their emails and tend to keep most anyway. We have an organisation wide email archive that keeps all emails but it is not PRA compliant." Regarding staffing one respondent wrote, "Staff do not think of emails as being functionally based - they think of format first and content second. There are also a variety of practices such as shared email folders, personal folders, shared fileserve folder which make the practical implementation of the schedule difficult."

Staff training was also a concern and one respondent wrote that, "We do not have an EDRMS which we can move email records into. Not all staff have been trained specifically in managing emails." Another respondent mentioned that their staff do not think of email as being functionally based but rather, "they think of format first and content second." Another respondent mentioned that end users tend not to understand that the content of an email, or email trail, will define its value as a business record. Of the perceived gaps they wrote, "The idea that email is your own and personal. Getting that across to staff that their 
email is an official record is a priority and information in the form of a brochure and talk is given at new staff inductions. The schedule covers all records, whether email or not."

Only one respondent commented that this question was not applicable to them as their institution's, “... General Disposal Authority is format neutral - i.e. it applies to all records regardless of format."

Question 8. Does the records management team work collaboratively with the IT Department in determining email retention?

This was the second scaled question of the questionnaire which, like the first, was scaled from 1 to 5 from 'Minimal collaboration' to 'Highly collaborative. This rating scale produced interesting results with the mode sitting at the middle amount of 3 , and the mean being 2.36. Proportionately most responses were on the lower end of the scale, with only one respondent saying that their records management team worked highly collaboratively with the IT Department. The skew is observable in Figure 3 with the median sitting at 2.5.

\section{Figure 3}

Does the records management team work collaboratively with the

IT Department in determining email retention?

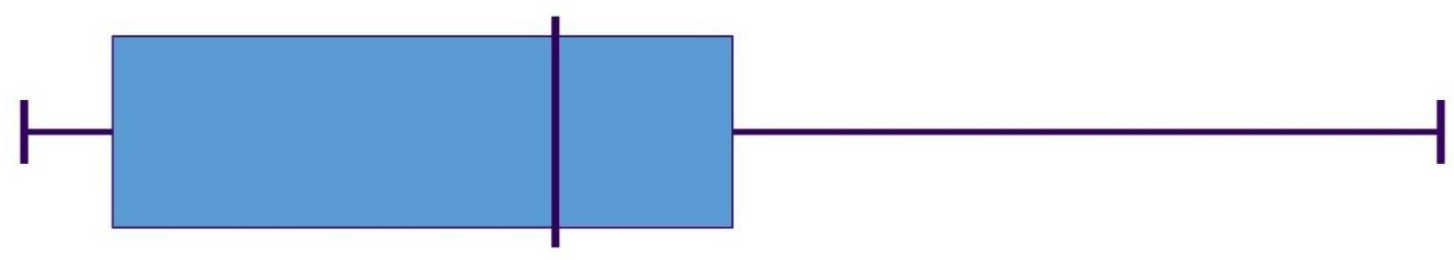

\begin{tabular}{lllllllll}
1 & 1.5 & 2 & 2.5 & 3 & 3.5 & 4 & 4.5 & 5 \\
\hline
\end{tabular}

Twelve of the respondents provided written responses in the discussion section. All but one went into detail regarding the collaboration with their institution's IT department. 
One respondent commented on the difficulty of answering this question as their information management team works closely and effectively with IT to deliver services, but not email retention. They wrote, "Difficult to answer; fundamentally, the information management team works closely and effectively with IT to deliver services - we don't work directly with IT on email retention."

Several participants mentioned ongoing discussion within their institutions. One respondent wrote, "The Records Advisor Role is currently based in Information Management Services team and feeds into specific IMS projects from a non-technical perspective. Like most RM roles, there is a debate as to where such a function sit within the institute." Another wrote, "We have had dialogues regarding this and I have been consulted when considering changes to the email system." Lack of collaboration was also mentioned and one respondent wrote, "They did not collaborate with me until after the email archive was purchased and were not concerned that it wasn't PRA compliant. I have not managed to get funds to update our EDRMS with a drag and drop function."

Regarding retention, for one respondent whose institution used Outlook, IT policy holds emails for 12 months before disposal. For another, they have an agreement with IT that no email records are disposed of until they can be sure the emails are being properly managed. Another wrote, "An enterprise-wide retention schedule applies to any types of documents inc. email, so we only need to work with the IT department to determine the email retention for the back-up files." In another tertiary institution, the IT department sometimes checks on the deletion of email, but usually in the context of retiring a server rather than an individual's email.

Question 9. Do you have an electronic system for the management of records (e.g. an EDRMS)?

This question was asked to find out what systems information professionals in tertiary institutions have employed to manage their records. By asking this question, further insight was sought into the responsibilities of the information management teams, as well as how emails were actively managed. 
Six respondents answered 'Yes', and eight respondents answered 'No' to having an electronic system to manage their records. The discussion section of this question generated the least amount of responses with only 6. Those who did expand on this question went into detail on what specific systems were in use, and also about research and projects undertaken by their teams.

Of those who have projects underway, one respondent wrote, "We are implementing this one area at a time and currently have most corporate areas live. Progress has stalled while we wait for a SharePoint upgrade and EDRMS systems upgrade." Another wrote, "We started a project 3 years ago to use SharePoint but this was put on hold because of other institute priorities. We currently have two institute activities (business reporting and policy development effectively managed in our SharePoint system."

For those without records management systems, or projects underway there were ongoing concerns. One of the respondents noted that, "The university does not have a dedicated EDRMS or equivalent, so lacks the technical infrastructure to properly support staff manage their email-as-records in contextualized repositories." Several respondents mentioned that currently email is stored on individual Outlook accounts with no inbuilt retention or disposal. If emails and their content are deleted, it may reflect the disposal authority but by good luck rather than good management.

One of the respondents was not so optimistic about the adoption of a records management system and they wrote, "Its a moot point as to whether having an EDRMS would make any difference in the management of emails as users still need to move emails into the EDRMS and therefore there is always the risk that an records (email) is not moved (as staff get busy, forget etc.)."

There were also concerns about legislation, and one respondent wrote:

We have done a fair amount of research into existing EDRMS solutions and have found that none meet our requirements. The business model of the companies that sell EDRMS in NZ are flawed in that they do not combine needed features in their basic package. Another problem is that vendors make promises they cannot keep, such as guaranteeing PRA compliance. At present we are considering using Microsoft Office 365 team sites with two records management plug-ins. It is our hope that this would bring us to about $95 \%$ compliance with the PRA. 
Question 10. What do you think the main risks are with regard to email management?

Although this question was not mandatory, all 14 survey participants responded. The intention behind this question and Question 11 was to get an idea of what the research participants felt were the main risks, and how they should be addressed.

Most respondents identified factors that related to legislation, as well as the actual management of the records.

Regarding legislation, one respondent wrote that the main risk was, "Privacy of those sending email to or from our organisation is easily breached. Privacy Act does not give permission for all emails to be captured and retained for ever just because that is convenient for the organisation. Email is not attached to policies, issues, actions and decisions that it refers to." Another wrote that there were standard risks such as, "... Lack of awareness that email represents a record; the blurring of lines between corporate and personal content; the difficulty of extracting email and storing it in centralized and dedicated repositories; it's immediacy and 'casual' nature, risk of privacy breaches and reputational damage via OIA release etc..."

The volume of email records, and the issue of staff management were also addressed with one respondent writing, "As most people tend to keep emails for accountability the main risks is that there is no system for linking to the relevant business activity." Another wrote that, "Important emails are lost amongst many unimportant. Although clearly stated that email are records, practicalities mean that they are usually treated as ephemeral." A third respondent also addressed this when they wrote, “... from an Records Management perspective the main risk is the sheer quantity of emails received and the lack of (automated) tools to assist organisations determining which emails are of short, medium and long term value."

Another respondent went into detail about the range of risks including the volume of emails and the end users being able to identify what constitutes a record:

Disconnection with all other institutional records due to a prevailing understanding by users that email is a record type in its own right rather than the content of the email identifying whether the email is a record or not. The volume of email and a user's capacity to identify 
emails as records is an issue. Where institute currently does not have an EDRMs that integrates with email, we are asking the user to make these decisions and become the records manager. Most users will not as it is perceive to take too long and they prefer the search capability of their own folder structure within Outlook and the search function (ok for individual not so much for institute).

Only one respondent specifically said that there was not a large risk with email management, "As it is mostly administrative and falls under the GDA6 don't think there is a huge risk."

Question 11. What changes would improve the management of email records?

This was an open-ended text discussion question that intended to gain an understanding of what would be beneficial on an institutional level, rather than the individual respondent's understandings of email management and the possible risks.

All 14 survey participants responded. To improve the management of email records, there were 5 main areas: Systems, Education and training, Policy Development, Automation, and Cloud servers. Figure 4 demonstrates the frequency that these themes are mentioned across the responses.

\section{Figure 4}

\section{What changes would improve the management of email records?}

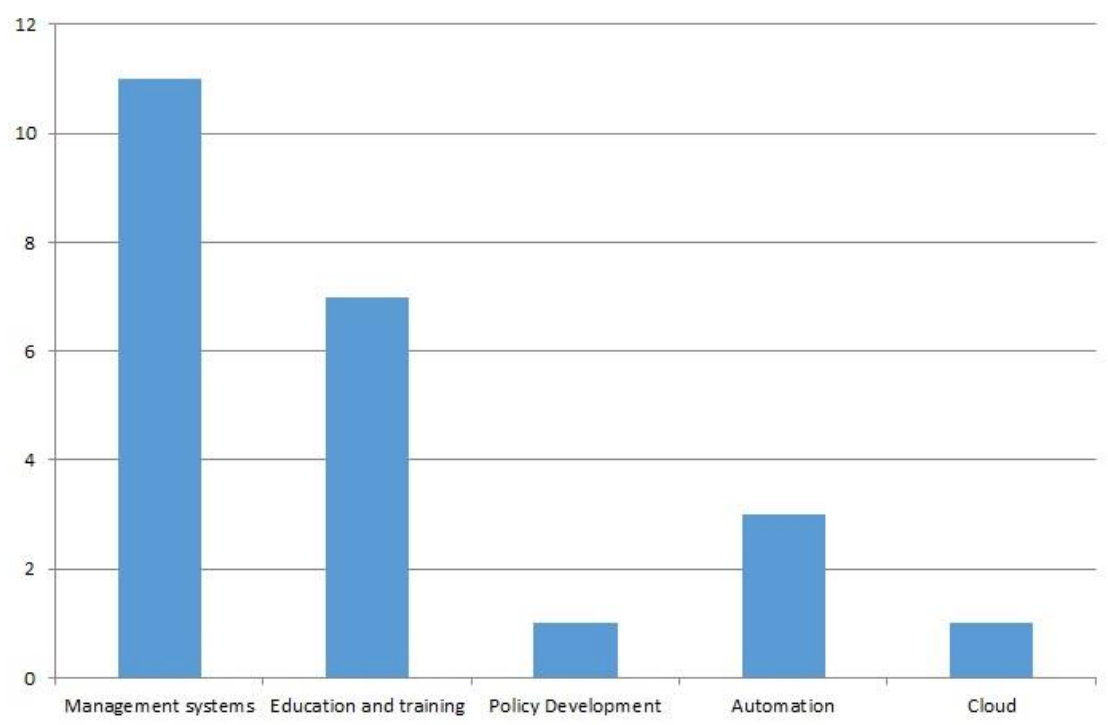




\section{Question 12. Final thoughts}

A final open-ended text question was included to capture further points of interest from the survey participants. The reason for this was that previous questions may not have provided the opportunities for the respondents to expand on their thoughts.

Eight respondents left final comments about the issues they have with email management as information professionals specifically operating within tertiary institutions.

Staffing was seen as an issue both with the resources given to the recordkeeping teams and the knowledge of end users. One respondent addressed the issue of staffing when they commented on organisational constraints saying that, "It is very hard to get effective resources for managing records in any form. I am currently only 0.2 FTE in this role which is clearly not enough to manage the records of over 200 staff." Another respondent was already looking forward to the next generation of staff stating that, "It will be interesting to see if the generation more used to social media as a form of both communication and information gathering will continue to use email to the same degree, and how this impacts on the management and use of email."

The systems that are in place for the management of email records were brought up again by respondents. One respondent wrote, "The development of IT systems that allow for emails to be managed seamlessly, shared appropriately, and that keep email conversations together (so users only look for one email)." Another respondent looked forward to implementing new tools when they wrote they would like to see, "... auto syncing to cloud made available so that staff can work offline and from anywhere, without removing information from the organisation"

Two respondents expanded on what they perceive as being important moving forward, including the need for a clear set of policies and procedures, and how records are perceived:

In all my time practicing RM (15 years) managing email has been a constant issue. Technology only goes someway to resolving the issues associated with email management and a change in culture and understanding of the value of email as a potential record. Businesses must understand that the technology will generally only do what you ask it to do so a very clear set 
of policies and processes that clearly identify responsibilities and expectations are important to guide this change of user understanding.

Email is a tricky one, because whilst decisions are made and recorded via it, it is still not universally seen as a record - until it is moved to another system e.g. an EDRMS. This is exacerbated by emails commonly being seen as a private domain i.e. the email address is connected to an individual, not a function based role, and is not usually open to all unit / division members.

\section{Discussion}

\section{Staffing}

As mentioned in the findings, six tertiary institutions had only one full time equivalent staff member or less, while the majority had two full time equivalent staff members or more. The records that are managed by the research participants are very similar between student records, and administrative records, without much differentiation between the two (see Figure 2). The differing result between management of administrative records and student records actually demonstrate a reversal in responsibilities. However, this does not mean that of the tertiary institutions that were surveyed they exclusively managed either student or administrative records. Instead it indicates that less information professionals look after student records. It may also indicate that for many tertiary institutions, the management of student records may be included as administrative responsibilities. There are also records that are neither administrative, nor do they belong to the student body. This includes general document management (both digital and electronic) which in turn encompasses staff email.

\section{Retention and disposal}

Appraisal policies and the retention and disposal schedules of tertiary institutions were covered over a series of questions. The first question of the set (Question 4) was to ascertain whether the surveyed tertiary institutions did in fact have policies in place. The unanimous response to this question was 'Yes'. While this cannot be extrapolated with $100 \%$ accuracy across the total sample population, it is promising that considerations are being made for the management of records in tertiary institutions. One of the aims of this research was to measure what appraisal measures are currently in place for digital records, 
specifically emails. $71 \%$ of the respondents to Question 5 replied positively that they do have procedures in place for the retention and disposal of email records in their policies. It was made very clear by research participants that in this particular environment the responsibility lies with the end user regardless of the systems or policies that are in place. This means that the responsibility for both identifying records worthy of retention, and taking the appropriate action with them, lies with the end user as has been discussed (Lewellen, 2015).

It is at this point that policies and procedures (or guidance) become more important. How policies and guidelines are presented and made accessible appears to differ between institutions though, and having them in place does not guarantee adherence. The main issue being that compliance by staff in the tertiary institutions was not monitored. Email as a format makes management of records even more difficult, and there were concerns about the lack of transparency over what content is held by any-one staff member and how locatable that information is. Bearing in mind the size of the staff responsible for the management of records within these institutions, one respondent noted that email in particular is difficult to manage effectively at an organisation wide level.

While it is difficult to monitor whether staff within tertiary institutions adhere to the guidelines or instructions for email management, it was important to find out whether records managers felt that the management of email records reflected their retention and disposal policy. As was indicated in Figure 2 of the findings, the results were skewed. This demonstrates that the actual practice of managing the retention and disposal schedules is not very reflective of the policies that the tertiary institutions have in place. The rating scale does not however take into account a lack of knowledge or observation by staff as was addressed in the prior question. Following on from the gaps between policies and practice, the survey participants were asked what they believed were gaps between the retention schedule and management of email records. As was mentioned, the two main issues are the systems in place, and the lack of accountability by the staff within the tertiary institutions.

Although a section of the questionnaire was dedicated to the implementation of EDRMS, it is interesting to see that this is a more pressing concern for the surveyed information professionals. The movement of information for the retention of physical hardcopies 
without an electronic management system in place was a concern that several respondents shared. This is because the actions taken by end users were not consistent throughout the institution. The format of extracted items requiring permanent retention could be as .msg or .pdf as examples, but really there is no way to know. Likewise, the location of these copies is often unknown as each staff member could have their own storage system within the institution's share drives which make the practical implementation of the schedule difficult.

This appears to be the case whether the institution's retention schedule is comprehensive or not. Other questionnaire participants believe that having the proper tool or system would help to decrease the current gaps in practice when email records are considered. Current research as was covered in the literature review supports these claims as government departments aim to meet legislative requirements (Lewellen, 2015). From the responses to Question 6 this it can be assumed that there are accepted organisational constraints which are why many of the surveyed tertiary institutions did not have EDRMS software to manage their electronic records. However, there were still perceived difficulties even with a system in place if it was not designed to suit the needs of the institution or information professionals. These concerns about whether EDRMS systems meet legislation were addressed by the text responses to Question 7.

The control over email records and their content is an ongoing issue in a recordkeeping environment when the responsibility lies in the hands of the end user. Aside from the systems in use, a significant gap in the retention of emails has been identified as the knowledge gap of end users in tertiary institutions. Staff awareness was found to be lacking among many survey participants as was demonstrated with text responses to Question 7. This reflects the research taken previously by Lips, Rapson and Hooper (Lips et al., 2008). An aspect of this was a lack of understanding by staff of what constitutes an email as a record and what action should be taken. In some cases the tertiary institution's General Disposal Authority is format neutral which reduces some of the knowledge gap. This is not the case for many tertiary institutions though, and the education of staff seems to be important as end users are not as able to make distinctions between format and content. 
Many survey participants rely on staff retaining what they identify as records, but they have no way of actually knowing how email records are being managed by individual staff members. The ad hoc, transient nature of emails is a concern for the research participants as was in the literature review (Baron, 2000).

\section{Relationships with IT}

EDRMS are an issue that were frequently mentioned by the information professions who responded to the questionnaire. Based on the literature it was assumed that this would be the case, as previous research has found that the implementation of systems differs from institution to institution (Lewellen, 2015). A component that affects this is whether the decision making around systems remains with the recordkeeping team or the IT department. Based on this it was important to gauge how the information professionals working in tertiary institutions felt about the possible divide between departments, and to assess where responsibilities in the institutions lie.

As was demonstrated by Question 8's rating scale (Figure 3), only one respondent felt that their department worked highly collaboratively with the IT department, while most felt that they somewhat collaborative. Half of the respondents felt that they had low or minimal collaboration with the IT department but without further information this might not necessarily have been a negative depending on where the tertiary institution based their decision-making. The involvement of IT departments with the retention of email records varied between institutions as was demonstrated by the rating scale results. The text responses to Question 8 further supported this notion. For some the disposal, or deletion, of emails falls solely with the IT department. The retention of email can also be affected by the amount of storage that is available. Depending on the specific institution's take on format, the relation with IT can differ again. The answers from the respondents also differed depending on whether they took email retention specifically into account or not. For a couple of research participants there seems to be ongoing discussion within their institutions of where functions and responsibilities lie. A benefit of open discussion is that those responsible for the management of records are able to provide input into projects (such as changes to email systems) from a non-technical perspective. On the other end of the scale, a lack of discussion and collaboration can leave information professionals feeling 
disjointed from the operations of the tertiary institution as was noted by the research participant who was provided with an EDRMS that is not PRA compliant.

With regard to collaboration with the IT department, EDRMS were again mentioned by the survey participants with one stating that there was no collaboration with the IT department beyond agreement that email management would be better with a system in place. The majority of survey participants did not have an EDRMS as was demonstrated in Question 9, but the difference in responses was not significant enough to determine whether the entire sample population reflects this. Most respondents, no matter what their present situation with system use is perceived some room for improvement. While progress is being made for some respondents who wrote text responses to Question 9, others identified organisational constraints as delaying the adoption of EDRMS software.

An important aspect of implementing an EDRMS is that it meets the legal requirements that are expected of tertiary institutions. It has been noted that one respondent mentioned that a lack of consultation from the IT department has jeopardised their ability to meet their legal requirements such as the PRA (Question 8). However, for the information professionals who are responsible for developing and implementing systems there are still issues with meeting their legal obligations based on what third-party software offers. Part of this comes back to the issue of staff knowledge gaps whether an EDRMS is in place or not. Without an automated process, the responsibility lies with the end user as was pointed out by one respondent to Question 9. The end user is expected to move emails into the electronic system as they carry out the record's first "moment of risk", meaning that there is the chance that emails may not be moved over, or emails that are not records are moved (Bearman, 2006; Lips et al., 2008).

\section{Risks to email records}

Throughout the findings, the risks associated with the management of email retention have been discussed. Questions 10 and 11 were asked to further understand what the information professionals working in tertiary institutions perceive as being the main risks of email management. The main points that were brought up in the open-ended text boxes were: Privacy, the volume and duplication of emails, staff knowledge gaps, capturing and retaining the 'record-ness' and metadata of email records. Several members mentioned loss 
of privacy, or privacy breaches, as being the main risks associated with the management of email records which is one of the key recordkeeping legislative concerns in New Zealand with the Privacy Act, 1993. Another aspect around privacy is the inadvertent loss of important records. The implications of loss of records, or breaches of privacy, not only mean that obligations go unfulfilled but also that the tertiary institutions have breached confidence of their stakeholders. Reputational damage is also imminent if the information ends up in the wrong hands, or misplaced information is requested via the Official Information Act 1982.

Along with the loss of information, there is also the risk of losing the vital information (authenticity, reliability, integrity and usability) that supports the core characteristics of records (Archives New Zealand, 2014b). The movement of email records or documents between different systems has been mentioned, but for this particular question several new points were brought up relating to the business activity or function of the email record. The lack of links between email and their metadata is one aspect, and another is the disconnection between all other institutional records. This is due to the systems that are in use, as well as a prevailing understanding by end users that email is a record type in its own right and not related to wider functions.

A contributing factor to the loss of records or information is the excessive volume of emails or the duplication of records. The 'big bucketing' method of appraisal is only applicable when the responsibility of records lies with information professionals (Findlay, 2014). In cases where the responsibility of records is with the end users, this leaves more room for error through information overload. The volume of emails exasperates the difficulty of locating information which in turn contributes to the loss of records and the follow-on legal ramifications. Important emails and their content are easily lost amongst many unimportant or personal communications. The duplication of documents is also an issue with staff as copies are retained for recordkeeping purposes, but without the right information being captured there is uncertainty about which document is the copy of the record or the original. Email presents problems that differ from other electronic documents, as it is difficult to know how many copies of a given email and its content exist, and who has them. Regarding the retention and disposal of these records, the back-up copies that end users 
may keep for their own personal records also need to be accounted for and disposed of in the same way as the originals.

The management of email records by the end user appears to be one of the biggest risks to come out of this research. This is the case whether the tertiary institution has an EDRMS or not. It is the individual staff, not the information professionals, who are required to maintain their emails and make judgements about what to keep. For many tertiary institutions it seems that there is a lack of awareness that email represents a record and that the blurring of lines between corporate and personal content. The idea that emails are personal extends to how end users access and use their email records. This is a concern as it can lead to lack of information sharing, and loss of information when staff leave the institution. The tangible level of risk that this presents to tertiary institutions or other organisations that share this business model is currently unknown.

\section{Looking forward}

The survey participants were lastly asked for their opinions on what changes would improve the management of email records, and what other thoughts they have about the associated issues. The retention and disposal of emails were mentioned by some respondents, but other areas for development received more attention. To address the issues in tertiary institutions presented by staff taking responsibility for their emails, education, awareness, and training were proposed. Ideally the training would be ongoing to increase user awareness of email management and the appropriate legislation such as the PRA, OIA 1982 and the Privacy Act, 1993. EDRMS can assist with the retention of emails but many respondents sought more seamless management tools with automation being an ideal feature. The benefit of automation being that it would take some pressure off the volume of email communications, and to varying degrees it would take the onus of the end user to make retention decisions. This way the management and retention of emails would remain within the system itself. Auto-syncing to a cloud system was also mentioned by one respondent so that there was no risk of staff removing confidential information from the organisation. With a clear set of policies in place, then the systems in place in tertiary institutions can be developed so that legal and institutional requirements are met. Although as has been mentioned there might not be $100 \%$ compliance. 
Current management of email records within tertiary institutions appears to fall within the Lifecycle model. This means that the records follow the stages of 'Creation or Receipt', 'Maintenance and Use', and 'Disposition'. The records remain with the end user until they are no longer being used, and at that point they become under the care of information professionals. Ideally the records would be under the care of information professionals from their inception, but with limited staffing and resources this is not possible. When considering the findings of this research from a Continuum perspective, the management of email records is still very much in the 'capture' axis of the spectrum. At the moment the information professionals who participated in the research are not in the position to guarantee the content and functions of the emails. Nor are they able to guarantee the organisation of records to facilitate their availability.

\section{Conclusion}

This project explored how email records are currently managed in New Zealand tertiary institutions. The purpose was to see what appraisal measures are currently in place for the retention of email records. It also sought to identify the main risks associated with the management, or mismanagement of records, and the current gaps between policy and practice. The main risks of email management that were identified in the findings were associated with the responsibilities of recordkeeping lying with the end user, rather than the information professionals. None of the research participants focussed on the appraisal policies that are in place, and so the identified gaps are not related to the retention schedules of records management but rather they are concerned with staff knowledge and practice. There is not enough insight amongst the information professionals of how staff within tertiary institutions currently manage their emails.

The lack of control around email records indicates that there is a strong possibility that the surveyed information professionals legislative requirements are not being met. To many research participants, implementing an EDRMS system appears to be step toward resolving this issue. As was mentioned in the literature review, EDRMS have the potential to save and preserve a record's evidential value (Lewellen, 2015). They also help with access by both making sure that the records are organised in such a way that others besides the end user can find the information, as well as restricting access so that the integrity of the record 
remains intact. Compliance with legislation is the main issue to consider when tertiary institutions are bringing in EDRMS. For research participants who have EDRMS in their tertiary institutions, there were mixed responses of how much ownership the information professionals had over the design and implementation of the system. This is reflected by where the responsibility of records retention lies. The consequences for those who did not have ownership, or who were not even consulted by the IT department, are evident. However, even those who were involved with the consultation process had their concerns.

As one of the main current risks with the management of email records within tertiary institutions is the responsibility of recordkeeping falling with the record's creator, information professionals need to have greater control over what actions the end users are taking. Internal self-assessment, or auditing would be recommended, especially considering the current state of email management. An appropriate development on this research would be to see how information professionals are actively looking after the risks posed by email management. Archives New Zealand has tools such as the Public Records Act Audit Self-Assessment Tool so that institutions can make sure that they are PRA compliant (Archives New Zealand, 2009d). The Public Records Act Audit Self-Assessment Tool takes most issues explored in this research into account including: training, ongoing observation of staff practice, systems, and the creation and capture of records (Archives New Zealand, 2009d).

Ongoing research and discussion is required so that the information needs and responsibilities within tertiary institutions are known. This needs to take place between those responsible for the management of records, as well as the IT department and those in senior management roles. If budget constraints are contributing to delayed projects, or outright preventing the implementation of EDRMS within institutions, then the information professionals within tertiary institutions need to advocate for their needs. It is not just to make the management of records easier, but also to make sure that legislative requirements are being met. Even if the retention of records such as email falls under the care of the IT department, there needs to be consultation so that the requirements are addressed. This is particularly the case if the IT department have more buy-in with the institution's senior management team. When it comes to budgetary concerns, any proposals relating to the implementation or development of EDRMS generally need to supported by 
tangible evidence. The risks that are posed by end users being responsible for the management of their records have been explored throughout this research but as one research participant mentioned, we currently do not know the actual cost of these risks. This is where the aforementioned auditing would be beneficial. Research into the cost of the risks associated with email, or even records, mismanagement needs to be undertaken in New Zealand so that information professionals can better advocate for their needs.

It has been established that EDRMS assist with recordkeeping and maintaining the core characteristics of records, but there is still the risk that they are not compliant with legislation. As one of the research participants mentioned, third-party EDRMS vendors often do not include essential features to guarantee PRA compliance. In other jurisdictions such as Australia, the National Archives of Australia (NAA) has published guidelines on implementing EDRMS in government agencies that goes from the information professionals through to senior management (National Archives of Australia, 2015). Archives New Zealand's Digital Recordkeeping Standard S5 has been mentioned as a point of consultation for the functionality of existing electronic systems, but it only establishes principles and good practice (Archives New Zealand, 2010). It would be beneficial for further research to be undertaken, or for guidelines to be developed so that, like the NAA, New Zealand agencies can be assisted with the implementation of EDRMS to ensure that they meet PRA requirements. Research may also need to be taken into the EDRMS software or vendors that are currently available in New Zealand to see how compatible their services are with New Zealand legislation. Tertiary institutions have a unique position under the PRA, but there is definitely scope for future research to extend out to the wider public sector. 


\section{References}

Archives New Zealand. (2006a, June 1). F1: Make a Record. Retrieved from

http://archives.govt.nz/sites/default/files/f1.pdf

Archives New Zealand. (2006b, June 1). F7: Recordkeeping Responsibilities. Retrieved from

http://archives.govt.nz/sites/default/files/f7.pdf

Archives New Zealand. (2009a). Digital Continuity Action Plan: Managing Information for Public

Sector Efficiency. Retrieved from

http://archives.govt.nz/sites/default/files/ActionPlanDoc.pdf

Archives New Zealand. (2009b, August 27). General Disposal Authority for New Zealand Universities.

Retrieved from http://archives.govt.nz/new-zealand-universities-appraisal-report

Archives New Zealand. (2009c, August 27). New Zealand Universities Retention and Disposal

Schedule. Retrieved from

http://archives.govt.nz/sites/default/files/DisposalScheduleDA337_3.pdf

Archives New Zealand. (2009d, August 27). Public Records Act Audit Self-Assessment Tool. Retrieved

June 11, 2015, from http://archives.govt.nz/public-records-act-audit-self-assessment-tool

Archives New Zealand. (2010, August). Digital Recordkeeping Standard: Recordkeeping Standard S5.

Archives New Zealand. (2011). Digital Continuity Action Plan. Retrieved May 5, 2015, from

http://archives.govt.nz/advice/digital-continuity-programme/digital-continuity-action-plan

Archives New Zealand. (2012). Continuum Resource Kit. Retrieved August 15, 2014, from

http://archives.govt.nz/advice/guidance-and-standards/continuum-resource-kit

Archives New Zealand. (2014a). Glossary Definitions Full List. Retrieved January 19, 2015, from

http://archives.govt.nz/advice/continuum-resource-kit/glossary/definitions-full-list\#E

Archives New Zealand. (2014b). Records Management Standard for the New Zealand Public Sector.

Archives New Zealand - Te Tari Taiwhenua. Retrieved from 
http://archives.govt.nz/sites/default/files/records_management_standard_for_the_new_ze aland_public_sector_-_publication_version_may_2014_0.pdf

Archives New Zealand. (2014c, September 19). Institutes of Technology and Polytechnics General Disposal Authority. Retrieved from http://archway.archives.govt.nz/ViewEntity.do?code=DA424\#

Archives New Zealand. (n.d.-a). General Disposal Authorities. Retrieved May 7, 2015, from http://archives.govt.nz/advice/guidance-and-standards/guidance-audience/advice-publicoffices/records-appraisal-and-dispos-1

Archives New Zealand. (n.d.-b). Information for New Zealand Polytechnics and Institutes of Technology. Retrieved May 7, 2015, from http://archives.govt.nz/advice/publicoffices/information-new-zealand-polytechnics-and-institutes-technology

Archives New Zealand. (n.d.-c). Information for New Zealand Universities. Retrieved May 7, 2015, from http://archives.govt.nz/advice/public-offices/information-universities Archives New Zealand - Te Rua Mahara o te Kāwanatanga. (2014). Appraisal and Disposal Information. Retrieved October 19, 2014, from http://archives.govt.nz/advice/guidance-andstandards/appraisal-and-disposal-information

Baron, N. S. (2000). Alphabet to email: How written English evolved and where it's heading. London: Routledge.

Bearman, D. (2006). Moments of Risk: Identifying Threats to Electronic Records. Archivaria, 62(Fall), $15-46$.

Cumming, K. (2012). State Records social media and recordkeeping survey results. Retrieved September 18, 2014, from http://futureproof.records.nsw.gov.au/state-records-socialmedia-and-recordkeeping-survey-results/

Cumming, K., \& Findlay, C. (2010). Digital recordkeeping: are we at a tipping point? Records Management Journal, 20(3), 265-278. 
Cumming, K., \& Picot, A. (2014). Reinventing appraisal. Archives and Manuscripts, 42(2), 133-145. http://doi.org/10.1080/01576895.2014.926824

Department of Internal Affairs. (2005). Public Records Act 2005. Retrieved from http://www.legislation.govt.nz/act/public/2005/0040/latest/whole.html

Department of Internal Affairs. (2014). ICT.govt.nz. Retrieved January 25, 2015, from https://ict.govt.nz/

Dorner, D. G. (2009). Public sector readiness for digital preservation in New Zealand: The rate of adoption of an innovation in records management practices. Building the Next-Generation Digital Government Infrastructures, 26(2), 341-348. http://doi.org/10.1016/j.giq.2008.11.003

Duranti, L. (2010). Concepts and principles for the management of electronic records, or records management theory is archival diplomatics. Records Management Journal, 20(1), 78-95. http://doi.org/10.1108/09565691011039852

Evans, S. J. (2015, March 3). Hillary Clinton "used an unsecured personal email account for her four years as Secretary of State - and then her aides decided which correspondence to hand over for the public record." Retrieved June 4, 2015, from http://www.dailymail.co.uk/news/article-2976803/Hillary-Clinton-used-unsecured-personalemail-account-four-years-Secretary-State-aides-decided-correspondence-hand-publicrecord.html

Feary, B. (2013). An annotated bibliography of multidisciplinary information security resources, for the purpose of maintaining privacy and confidentiality in New Zealand government records management. Retrieved from http://researcharchive.vuw.ac.nz/bitstream/handle/10063/2824/thesis.pdf?sequence=2

Findlay, C. (2014, May). Reinventing Archival Methods in The Hague. Retrieved December 9, 2014, from http://rkroundtable.org/2014/02/05/reinventing-archival-methods-in-the-hague/ 
Gay, L. R., Mills, G. E., \& Airasian, P. W. (2009). Educational research: Competencies for analysis and application (9th ed.). Upper Saddle River, NJ: Merrill/Pearson Education.

Greene, J. C., \& Caracelli, V. J. (1997). Defining and describing the paradigm issue in mixed-method evaluation. New Directions for Evaluation, 1997(74), 5-17.

Greer, R. C., Grover, R. J., \& Fowler, S. G. (2007). Introduction to the library and information professions (2nd ed.). Libraries Unlimited.

Institute of Culture, Discourse \& Communication, AUT University. (2013). The Internet in New Zealand 2013. Auckland, New Zealand.

Ismail, A., \& Jamaludin, A. (2009). Towards establishing a framework for managing trusted records in the electronic environment. Records Management Journal, 19(2), 135-146. http://doi.org/10.1108/09565690910972084

Johnston, L. (2012). An investigation into the attitudes of archivists towards the use of social media at Archives New Zealand (MIS Research Report). Victoria University of Wellington, Wellington, New Zealand. Retrieved from http://hdl.handle.net/10063/2860

Joseph, P., Debowski, S., \& Goldschmidt, P. (2012). Paradigm shifts in recordkeeping responsibilities: implications for ISO 15489's implementation. Records Management Journal, 22(1), 57-75. http://doi.org/10.1108/09565691211222108

Lappin, J. (2014, November). Can records management be automated?. Presented at the DLM Forum, Lisbon, Portugal. Retrieved from http://purl.pt/26107/1/DLM2014_PDF/08\%20\%20Can\%20records\%20Management\%20be\%20automated.pdf Lappin, J. (2015, April 30). Policy advice on e-mail from different national archives. Retrieved May 7, 2015, from http://thinkingrecords.co.uk/2015/04/30/policy-advice-on-e-mail-fromdifferent-national-archives/

Leedy, P. D., \& Ormrod, J. E. (2013). Practical Research: Planning and Design (10th ed.). New Jersey: Pearson. 
Lewellen, M. J. (2015). The Impact of the Perceived Value of Records on the Use of Electronic Recordkeeping Systems. Retrieved from http://researcharchive.vuw.ac.nz/bitstream/handle/10063/4144/thesis.pdf?sequence=2

Lips, M., \& Rapson, A. (2009). Emerging records management in 21st century New Zealand Government-part 2 (Unpublished report). Victoria University of Wellington. Retrieved from http://researcharchive.vuw.ac.nz/handle/10063/1593

Lips, M., Rapson, A., \& Hooper, T. (2008). Research Report "E-mail Records Management in 21st Century New Zealand Government." Retrieved from http://researcharchive.vuw.ac.nz/bitstream/handle/10063/1592/research\%20project.pdf?s equence $=1$

Ministry of Education. (2015). Tertiary Providers. Retrieved January 6, 2015, from http://www.educationcounts.govt.nz/data-services/directories/list-of-tertiary-providers National Archives of Australia. (2011). Implementing an EDRMS - Key Considerations. Retrieved from http://www.naa.gov.au/Images/EDRMS-key-considerations_tcm16-47289.pdf

National Archives of Australia. (2015). Electronic document and records management system (EDRMS). Retrieved June 11, 2015, from http://www.naa.gov.au/recordsmanagement/agency/digital/EDRMS/index.aspx

National Archives \& Records Administration. (2013, August 29). NARA Bulletin 2013-02. Retrieved May 8, 2015, from http://www.archives.gov/records-mgmt/bulletins/2013/2013-02.html Nguyen, L. T., Swatman, P., \& Fraunholz, B. (2007). EDMS, ERMS, ECMS or EDRMS: fighting through the acronyms towards a strategy for effective corporate records management. ACIS 2007 Proceedings, 122.

Public Record Office. (1999). Management, appraisal and preservation of electronic records. Vol 1: Principles. The National Archives. Retrieved from http://collections.europarchive.org/tna/20080108103210/http:/www.nationalarchives.gov. uk/documents/principles.pdf 
Shroff, M. (2005, June). The Official Information Act and Privacy: New Zealand's Story. Presented at the FOI Live 2005 Conference, London. Retrieved from http://www.humanrightsinitiative.org/programs/ai/rti/international/laws_papers/newzeala nd/official_info_act_privacy_newzealand_story.pdf

Statistics New Zealand. (2006). Government Use of Information and Communication Technology. Retrieved January 19, 2015, from http://www.stats.govt.nz/browse_for_stats/government_finance/central_government/Gov ernmentUseofInformationandCommunicationTechnology_HOTP06.aspx

Statistics New Zealand. (2013). Information and Communication Technology Supply Survey: 2012. Retrieved from http://www.stats.govt.nz/browse_for_stats/industry_sectors/information_technology_and_ communications/ICTSupplySurvey_HOTP11-12.aspx

Stoks, R. K. (2012). Taming the Wild West: Capturing Public Records Created on Social Media Websites (MIS Research Report). Victoria University of Wellington.

Upward, F. (1996). Structuring the Records Continuum - Part One: Postcustodial principles and properties. Archives and Manuscripts, 24(2), 268- 285.

Upward, F. (2005). In S. McKemmish, M. Piggott, B. Reed, \& F. Upward (Eds.), Archives: recordkeeping in society (pp. 197 - 222). Wagga Wagga: Elsevier.

Vance, A. (2014, December 22). PM John Key's text message deleting examined. Retrieved June 4, 2015, from http://www.stuff.co.nz/national/politics/64399395/pm-john-keys-text-messagedeleting-to-be-examined

Vance, A. (2015, January 4). History in bin when the PM deletes texts. Retrieved June 4, 2015, from http://www.stuff.co.nz/national/politics/opinion/64642468/history-in-bin-when-the-pmdeletes-texts

Ward, J. (2006). Quantity does matter: records management for billions of documents. KM World Best Practices White Paper, 15(9). 
Whittaker, S., Bellotti, V., \& Gwizdka, J. (2006). Email in personal information management.

Communications of the ACM, 49(1), 68-73.

Zwarich, N., \& Park, E. G. (2013). E-Mail Management in the Canadian Government: Overview of the Practices from a Records Management Perspective. Presented at the Proceedings of the Annual Conference of CAIS/Actes du congrès annuel de l'ACSI. 


\section{Appendix A}

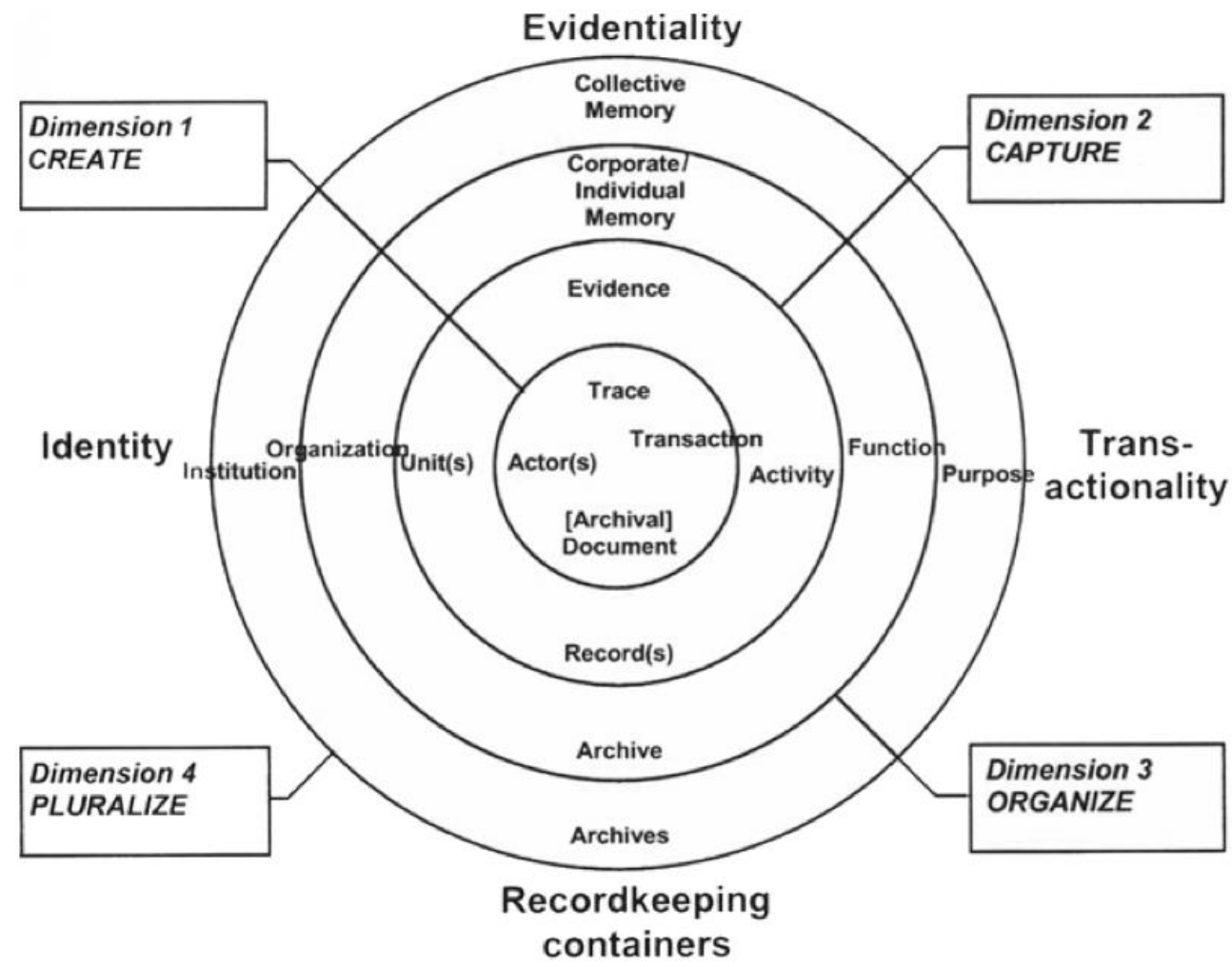

Records Continuum: (Upward, 1996) 


\section{Appendix B}

Dear XXXX,

My name is Morgan Gradwell and I am a student at Victoria University of Wellington. I am conducting research in partial fulfilment of a Master of Information Studies. The project I am undertaking is examining the appraisal of email records in New Zealand tertiary institutions. This research project has received approval from the Victoria University School of Information Management Human Ethics Committee.

I am inviting information professionals working with institutional records to participate in this study. It is hoped that this study will gain insight into the current appraisal measures being used within New Zealand public sector institutions. This is specifically with regards to New Zealand tertiary institutions that are Crown Entities, and therefore subject to the Public Records Act 2005. If you are not the best staff member to participate, it would be greatly appreciated if you could forward this onto the relevant employee in your institution.

The research aims to identify any current gaps in guidance and in the practice of the retention and disposal of email records. The research does not aim to produce a governance or best-practice framework. Instead by focussing on tertiary institutions it aims to provide a foundation for further research and identify the needs within tertiary institutions that may be reflected within the wider public sector.

Participants will be asked to complete an online questionnaire. You may choose not to participate. However, kindly note, participants will not be able to withdraw from the survey once they have submitted the survey, since their data will be anonymous. Submitting the survey will be regarded as consenting to participation. The questionnaire will involve both rating scales and discussion items. It is envisaged that the questionnaire will take about twenty minutes to complete and may be completed in your own time. The end date for completing the questionnaire is May 42015.

You may participate in the survey by following this link: http://vuw.qualtrics.com/SE/?SID=SV 9NxB6cSEoOxEcLP

Responses will form the basis of my research project and will be put into a written report on an anonymous basis. It will not be possible for you to be identified personally, or for your place of work to be identifiable. Grouped responses will be presented in this report but individual statements used in discussion items may be quoted directly. All material collected will be kept confidential. No other person besides me and my supervisor Gillian Oliver will see the questionnaire responses.

As it will not be known who participated in the questionnaire, a summary of findings will be sent to the initial points of contact to whom email invites were sent. The final report will be submitted for marking to the School of Information Management and deposited in the 
University Library which includes an online repository. Questionnaire responses will be disposed of after 2 years.

There is the possibility that the findings will be disseminated at academic or professional conferences due to the aim that this research will provide a foundation for further research. Similarly, there is the possibility that the final report will be published in academic or professional journals to disseminate the research.

If you have any further questions or would like to receive further information about the project, please contact me at 027637 3210, gradwemorg@myvuw.ac.nz or my supervisor Gillian Oliver at the School of Information Management at Victoria University (04) 463 7437, gillian.oliver@vuw.ac.nz.

Kind regards, Morgan Gradwell 


\section{Appendix C}

\section{Managing email records}

Q1 How many full time equivalent staff members are employed to manage records at your tertiary institution?

O $0-1(1)$

2-3 (2)

O $4-5(3)$

$5+(4)$

Q2 Does the records management team look after administrative records?

Yes (1)

No (2)

Q3 Does the records management team look after student records?

Yes (1)

No (2)

Q4 Do you have a retention and disposal schedule?

Y Yes (1)

No (2)

Onsure (3)

Answer If "Do you have a retention and disposal schedule?" Yes Is Selected

Q5 Are there procedures for the retention and disposal of email records in your policies?

Y Yes (1)

No (2)

O Unsure (3)

Q5a Comments: 
Answer If "Do you have a retention and disposal schedule?" Yes Is Selected

Q6 Does the actual practice of managing email records reflect retention and disposal policy?

\begin{tabular}{|c|c|c|c|c|c|}
\hline $\begin{array}{c}\text { Not very } \\
\text { reflective:Highly } \\
\text { reflective (1) }\end{array}$ & 0 & $2(1)$ & $3(3)$ & $4(4)$ & $5(5)$ \\
\hline
\end{tabular}

Q6a Comments:

Answer "If Do you have a retention and disposal schedule?" Yes Is Selected

Q7 What are the gaps between your schedule and the management of email records?

Q8 Does the records management team work collaboratively with the IT Department in determining email retention?

\begin{tabular}{|c|c|c|c|c|c|}
\hline $\begin{array}{c}\text { Minimal } \\
\text { Collaboration:Highly } \\
\text { Collaborative (1) }\end{array}$ & $1(1)$ & $2(2)$ & $3(3)$ & $4(4)$ & $5(5)$ \\
\hline
\end{tabular}

Q8a Comments:

Q9 Do you have an electronic system for the management of records (e.g. an EDRMS)?

O Yes (1)

No (2)

O Unsure (3)

Q9a Comments:

Q10 What do you think the main risks are with regard to email management?

Q11 What changes would improve the management of email records?

Q12 If you have any last thoughts to contribute to this research project, then please add them below: 